\title{
Learning Disorder Secondary Epilepsy: A Case Report
}

\section{Andréa Rose de Albuquerque Sarmento Omena1, José Cláudio da Silva² ${ }^{2}$ Camila Maria Beder Ribeiro Euclides Maurício Trindade Filho ${ }^{3 *}$, Terezinha Rocha Almeida ${ }^{4}$}

${ }^{1}$ Cesmac. Clínica Guri, Maceió, Brazil

${ }^{2}$ Universidade Estadual de Ciências da Saúde de Alagoas-UNCISAL, Maceió, Brazil

${ }^{3}$ Universidade Estadual de Ciências da Saúde de Alagoas (NUCIB-UNCISAL), Maceió, Brazil

${ }^{4}$ Clínica Guri, Maceió, Brazil

Email: andreasarmento7@hotmail.com,jcsneuroc1@gmail.com,camilabeder@hotmail.com, *emtfilho@gmail.com, teca_jurity@yahoo.com.br

How to cite this paper: de Albuquerque Sarmento Omena, A.R., da Silva, J.C., Ribeiro, C.M.B., Filho, E.M.T. and Almeida, T.R. (2016) Learning Disorder Secondary Epilepsy: A Case Report. World Journal of Neuroscience, 6, 303-309.

http://dx.doi.org/10.4236/wjns.2016.64033

Received: September 14, 2016

Accepted: November 8, 2016

Published: November 11, 2016

Copyright $\odot 2016$ by authors and Scientific Research Publishing Inc. This work is licensed under the Creative Commons Attribution International License (CC BY 4.0).

http://creativecommons.org/licenses/by/4.0/

\begin{abstract}
Introduction: Epilepsy is a syndrome characterized by the presence of seizures that can affect the cognitive performance of the individual. Neuropsychology has studied the idiopathic epilepsies to understand if the behavioral and cognitive impairments are associated with electrical discharges in the brain, and not with an injury itself. Objective: To identify cognitive impairments of a child with epilepsy associated with diagnosis of learning disorder. Method: The sample consists of a child diagnosed with epilepsy, nine years old, from Maceió-AL. The methodology applied is a qualitative and descriptive study of a case report. Neuropsychological tests are applied for that purpose. Results: The results of the tests show cognitive deficits, impaired attention, memory and slowness of reasoning. Conclusion: Despite the results, it cannot be said in this case that epilepsy was the only factor that triggered the learning disorder, because the child had related comorbidities.
\end{abstract}

\section{Keywords}

Epilepsy, Learning Disorder, Cognitive Functions

\section{Introduction}

The International League Against Epilepsy (ILAE) in 2005 defined Epilepsy as a disorder of the brain characterized by a predisposition to generate epileptic seizures [1]. Epilepsy is usually seen as a traumatic condition. Even today, with more information and knowledge about the disease, it is a condition that could prejudice behavioural 
abilities of patients [2]. It is a disease that affects cognitive function compromising learning [3].

The constant difficulties of the patient who has epilepsy during the learning process, together with the social and family environment, make them more likely to suffer from anxiety [4]. Considering these aspects, precocious diagnosis and treatment, providing less loss of life quality is the primary goal of the health team, school and family. Deep understanding of neurological and educational mecanism involved in this pathology has been the challenge of researchers from different scientific areas.

From the data presented, it is significant to learn about disorders associated with epilepsy. Therefore, this research aims to determine which cognitive impairment may have a child diagnosed with epilepsy and learning disorders. Although many children with epilepsy have few difficulties in social and cognitive development, the literature shows that epilepsy is associated with increased risk for a variety of behavioral and learning problems. Children with epilepsy commonly show a discrepancy between academic performance and intellectual ability [5]. The most frequent complaints are: difficulty of memory, slowing of reasoning and lack of attention. In turn, patients with epilepsy are still important source of knowledge to neuropsychology, i. e., studies with epileptic patients have contributed to the knowledge of the workings of the brain and cognitive function.

\section{Materials and Methods}

This study was executed according to the Resolution 466/12, after approved by the Institutional Ethical Committee, with protocol of number 418,738 on 16/10/2013.

The sample consisted of a child diagnosed with epilepsy referred by a neurologist. The patient is a nine years old, male, attending third grade at a public school in the state of Alagoas.

This is a case report in which we used the qualitative and descriptive method which allows us to study in depth, systematic discussion of a particular case.

\section{Study Procedures}

Responsible for the child was invited to participate of the study. At this moment, it was explained and presented the document of informed consent, as well as the commitment of statements with the results and allocation of materials and/or data collected. It was explained also the child with adequate language, and dates of the sessions have been set.

The materials used were psychological tests: WISC III, Raven and complex figure of Rey, Psychological anamnesis, neurological evaluation, educational and behavioral school performance reports.

The Wechsler Intelligence Scale for Children or WISC III is a clinical tool for individual application, to assess the intellectual capacity of children aged 6 years to 17 years old [6].

Coloured Progressive Matrices Raven can be described as "observation tests and 
clarity of thought", and aims to assess general intelligence [7].

Complex figures of Rey is one of the 10 most commonly used neuropsychological tests in the world, due to the variety of cognitive processes designed to measure, such as: constructive praxia, planning, strategies for problem solving, perception, motor function and visual memory [8].

Data Analysis Method: Comparative and there was the confrontation of data obtained in the case study with the data found in the search.

Finally, we evaluated the results obtained in the tests, and then delivered the child to the responsible.

\section{Case Description}

LHFS, nine years old, born in $02 / 02 / 2004$, is a male, in the third year of elementary school, and native of Alagoas, Brazil. According to mother's reports, the pregnancy was accidentally diagnosed in a CT (made use of iodinated contrast media). It was a high-risk pregnancy because the mother was using chemotherapy to treat ovarian cancer and right horn. It was mooted the possibility of interrupt the pregnancy, but after contact with the doctor's Cancer Institute of Rio de Janeiro was chosen for its maintenance, but was very eager for pregnant women terminate the pregnancy. The pregnant reported that had periods of negative emotions, conflicts and difficulties in the relationship with her husband. It was a term pregnancy, caesarean delivery, and no fetal distress.

The child had adequate psychomotor development for age, tone of neck at the three months. Sat without any support at seven months, crawled at eight months and walked at 12 months, spoke the first words between 10 to 12 months. Among common childhood diseases had chickenpox. At 3 years old he had an epileptic seizure. He suffered three falls with fractures of the upper limbs. Two hospitalizations due to three surgeries (phimosis, umbilical hernia and fracture). Mother of the child refers as main complaint the poor school performance and heteroaggressiveness He can read little, can not write, don't knows money, as well as days of the week and hours. He began to show aggression, neuropsychomotor agitation and seizures to the three years of life. Guided by the school, the genitor sought a neurological assessment, due to the child assaulting other children. Was performed an electroencephalogram (EEG) and epileptogenic activities were detected predominantly in temporo-parietal-occipital areas, and initiated treatment with carbamazepine and pericyazine.

The mother states that maternal uncle has epilepsy and also reports occurrence of migraine (maternal aunt, mothers' and grandmother). Patient were avaluated by liver and kidney functions, blood count and computerized electroencephalography (EEG). He was diagnosed with temporal lobe epilepsy, secondarily by external causes-disease of pregnancy and iatrogenic medicines during the pregnancy), i.e. ICD10: G40. 3-epilepsyF71-moderate mental retardation. He was treated with carbamazepine $200 \mathrm{mg}$, gardenal $100 \mathrm{mg}$ and risperidone $1 \mathrm{mg}$. 


\section{Results}

During neuropsychological assessment, he agreed to perform all activities. He performed the following assessments: HTP test, he showed no interest. In all drawings the child finished saying it could not draw any detail in the drawing. He did quickly what was requested. The test was used to the purpose of establishing rapport. Coloured Progressive Matrices of Raven, He showed interest in the test, but had difficulty sustaining attention. Finished the test in 12 minutes and achieved total score of 17 points, percentil of 30 and classified in Grade III that ranks him intellectually in the level average. The deficit scale of attention/hyperactivity disorder: Was requested to his teacher to fill the Scale of Deficit Disorder Attention/Hyperactivity Disorder. According to the results, using as reference the table of date to the sex male of the public schools (state and municipal), He showed an attention déficit of 62 points, percentile equal to $65 \%$, demonstrating difficulty more significant in this area. He don't finishes the tasks, is distracted by any stimulus, it finds difficult to concentrate and to listen. He presents some mild symptoms of hyperactivity/impulsivity: stand up often of portfolio, moves hands and feet constantly. Considering the learning problems, no improvement in learning the Portuguese language was observed, has difficulties to understanding math problems and expressing your thoughts verbally, slow reasoning, writes with errors and is slow to perform tasks. WISC III: According to the results (Table 1 and Table 2) achieved with the application of the WISC III in verbal scale, verbal IQ, including

Table 1. Weighted points equialent to gross income.

\begin{tabular}{|c|c|c|c|c|c|c|c|}
\hline Subtests & $\begin{array}{l}\text { Gross } \\
\text { points }\end{array}$ & & & Weighted & ts (WP) & & \\
\hline To complete Figures & 11 & & 08 & & 08 & & \\
\hline Information & 5 & 05 & & 05 & & & \\
\hline Code & 11 & & 03 & & & & 03 \\
\hline Similarities & 8 & 10 & & 10 & & & \\
\hline $\begin{array}{l}\text { Arrangement of } \\
\text { Figures }\end{array}$ & 2 & & 04 & & 04 & & \\
\hline Arithmetic & 10 & 05 & & & & 05 & \\
\hline Cubes & 2 & & 05 & & 05 & & \\
\hline Vocabulary & 17 & 09 & & 09 & & & \\
\hline Assemble Objects & 8 & & 06 & & 06 & & \\
\hline Comprehension & 14 & 12 & & 12 & & & \\
\hline $\begin{array}{l}\text { (Looking for } \\
\text { Simbols) }\end{array}$ & 10 & & (07) & & & & (07) \\
\hline (Digits) & 4 & $(02)$ & & & & $(02)$ & \\
\hline Maze & 18 & & $(0)$ & & & & \\
\hline \multirow[t]{2}{*}{ Sum of the WP } & & 41 & 26 & 36 & 23 & 07 & 10 \\
\hline & & Verb & Exec & C.V. & O.P. & R.D. & V.P. \\
\hline
\end{tabular}


subtests (information, similarities, arithmetic, vocabulary, comprehension) have obtained percentile 21 and classificated as average low. In the execution scale, performance IQ, which include the subtests (to complete figures, codes, figures arrangement, cubes, assemble objects) he obtained 01 percentile and intellectually clasified as deficient. The scores in relation to the verbal comprehension index remained in the average; index of perceptual organization and processing speed were classified as in limit and resistance index to distraction as intellectually deficient.

The test of Complex Figure Rey (Figure 1) was used according to the age of the patient. In the step of picture playback, was observed the immediate memory. He started drawing in details, and then copied the elements next, resulting in a distorted copy. The Pacient was identified as Type IV due to juxtaposition of details. He made the copy in 8 minutes and obtained percentile of 10, classifying him as below of a standard deviation. When prompted to perform the drawing by evocation initially the pacient showed resistance, saying that didn't know, but was encouraged to do what he remembered. He made a quick drawing in 2 minutes and with few elements getting a percentile of 10 , clearly insufficient.

The patient showed multiple cognitive impairments, affecting several cognitive functions. However, despite the finding it was not possible to confirm that the epilepsy

Table 2. IQs equivalents to the sum of weighted points.

\begin{tabular}{ccccc}
\hline Scale & Sum of weighted points & IQ Scores & Percentile & Interpretation \\
\hline Verbal & 41 & 88 & 21 & Average lower \\
Execution & 26 & 67 & 1 & Intellectualy disabled \\
Total & 67 & 76 & 5 & Limitrophe \\
Verbal Comprehension & 36 & 93 & 32 & Average \\
Perceptual Organization & 23 & 72 & 3 & Limitrophe \\
Resistance to Distraction & 7 & 63 & 1 & Intellectualy disabled \\
Cognitive Processing Speed & 10 & 71 & 3 & Limitrophe
\end{tabular}
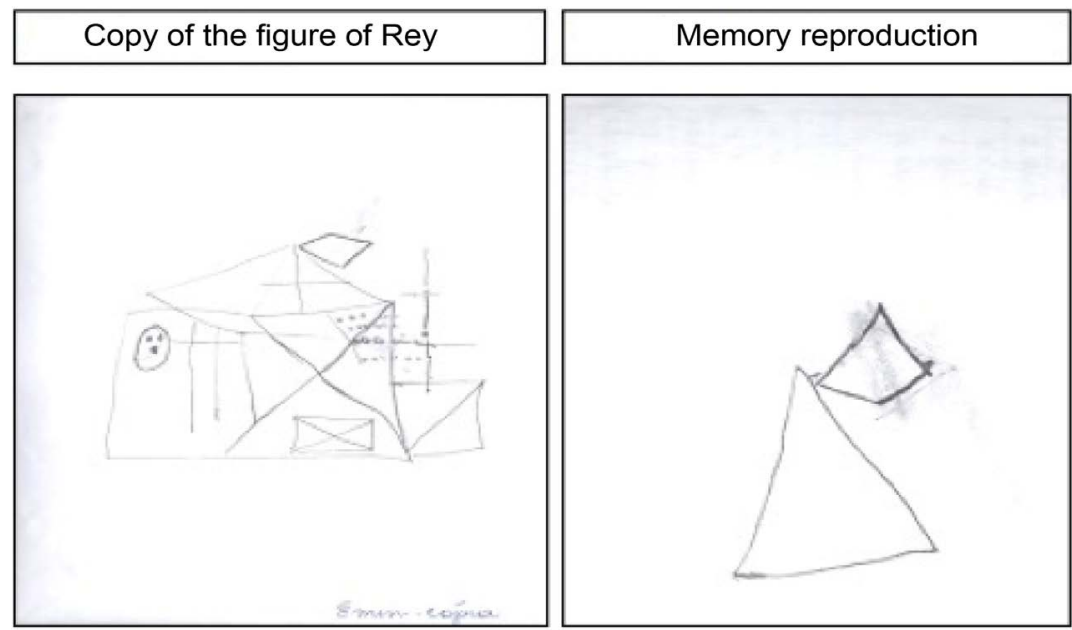

Figure 1. Complex figures of Rey. 
is the sole cause of learning disorders, since in the analysis studied was observed multiple comorbidities. Therefore, it can be said that the learning disorder is multifactorial causes.

\section{Discussion}

It was observed in the results of the subtests of the WISC III, that assess the attention and cognitive processing speed, difficulty in maintaining attention and slowing of cognitive processing. Similarly, in the subtests that assessed executive functions, planning, perceptual organization, the logical reasoning and immediate memory were obtained below scores of a standard deviation. Corroborating what Fuentes (2008) stated in other neuropsychological studies of patients with epilepsy we observed several executive skills, such as concept formation, abstract thinking, mental flexibility, mental processing and planning.

The subtests digits and arithmetic comprise the resistance scale at distraction (Wechsler, 2002). The patient showed a facility to losing the focus of the context, and according to these subtests was classified as intellectually deficient, according to the results obtained in the deficit scale of attention/hyperactivity.

In subtests of the WISC III, where the patient was asked to build and assemble elements of two and three-dimensional in space, He presented difficulties to perform movements under command or imitation. However, not presented alteration of motor functions and visuo-perceptual, which suggested presenting constructive apraxia. According to Gomez (2012) in the absence of comprehension deficit, sensitivity or muscle strength, constructive apraxia it is characterized by difficulty in performing movements under command or imitation.

In the Matrices Progressive Raven's test, it became clear that the patient present no alterations in the visual input (visual perception). His performance in the test was inversely proportional to the need of academic knowledge to answer. In Complex Figure Rey test, He presented poor planning and immediate memory.

According to analysis, the patient in question, showed significant deficits in attentional system, visuo-constructive perception, organizational ability, memory and slowing of reasoning. His intellectual capacity was lower than expected for children of their age and education. Diniz (2010) states that are described attentional alterations, of executive functions and general intelligence level in patients with epilepsy. The evaluation Neuropsychological added important data for treatment planning. However, one can not say that the learning disorder is due exclusively epilepsy, as they may be associated with the comorbidities of the case.

\section{Final Considerations}

This research does not exhaust all the possibilities to evaluate the disorder of secondary learning to epilepsy, but contributes to new fields of study. Individual study (case study), when minutely detailed, will guide the studies of greater magnitude and breadth. 
In this context, the neuropsychological assessment is crucial to trace the neuropsychological profile of the patient, and a good evaluation should start in the interview. Thus, after data collection neuropsychological tests will be applied. In a way, the essential purpose of a neuropsychological battery is the overall assessment of cognitive functions by specifying the dysfunctions of attention, memory, language and executive functions that are basis for the development of intellectual abilities. Thus, the neuropsychological assessment contributes to a multidisciplinary understanding of the case in study of this research.

Thus, the learning disorder secondary to epilepsy was evaluated by taking into account the results of tests that were applied to the patient and medical history with the mother, and with support from reports of the schools/teacher, which were the pillars to realize that the patient in this study had learning disorders, making it impossible to say that his diagnosis of epilepsy was responsible to cause only all comorbities.

It is recommended that the professionals involved with patients with learning disability observe the results obtained by neuropsychological assessment, with a view to detecting the needs of changing therapeutic project, allowing improvement of the treatment in order to find strategies that improve techniques habilitation/rehabilitation and more appropriate therapies, thereby improving the psychomotor development and social interaction to better socialize the individual in your world.

\section{References}

[1] Fisher, R.S., et al. (2014) ILAE Official Report: A Practical Clinical Definition of Epilepsy. Epilepsia, 55, 475-482. http://dx.doi.org/10.1111/epi.12550

[2] Fernandes, P.T. and Li, M.L. (2006) Percepção de Estigma na Epilepsia. Journal of Epilepsy and Clinical Neurophysiology, 12, 207-218. http://dx.doi.org/10.1590/s1676-26492006000700005

[3] Moreira, F.D.S., De Lima, A.B., Fonseca, P.C. and Maia Filho, H.D.S. (2014) Mental Health of Children and Adolescents with Epilepsy: Analysis of Clinical and Neuropsichological Aspects. Arquivos de Neuro-Psiquiatria, 72, 613-618. http://www.scielo.br/scielo.php?script=sci_arttext\&pid=S0004282X2014000800613\&lng=en \&nrm=iso\&tlng=en http://dx.doi.org/10.1590/0004-282X20140098

[4] Fernandes, P.T. and De Souza, E.A.P. (1999) Inventário simplificado de qualidade de vida na epilepsia infantil: Primeiros resultados. Arquivos de Neuro-Psiquiatria, 57, 40-43. http://dx.doi.org/10.1590/S0004-282X1999000100008

[5] De Souza, E.A.P. (1999) Qualidade de vida na epilepsia infantil. Arquivos de NeuroPsiquiatria, 57, 34-39. http://dx.doi.org/10.1590/s0004-282x1999000100007

[6] Wechsler, D. (2002) WISC-III: Escala de Inteligência para Crianças: Manual, 3 edição. Adaptação e padronização brasileira de Vera Lúcia Marques de Figueiredo. Casa do Psicólogo, São Paulo.

[7] Bandeira, D.R., Alves, I.C.B., Giacomel, A.E. and Lorenzatto, L. (2004) Matrizes Progressivas Coloridas De Raven-Escala Especial: Normas Para Porto Alegre, Rs (The Raven's Coloured Progressive Matrices: Norms for Porto Alegre, RS). Psicologia em Estudo, 9, 479-486.

[8] Jamus, D.R. and Mäder, M.J. (2005) A Figura Complexa de Rey e Seu Papel na Avaliação Neuropsicológica. Journal of Epilepsy and Clinical Neurophysiology, 11, 193-198. 
Submit or recommend next manuscript to SCIRP and we will provide best service for you:

Accepting pre-submission inquiries through Email, Facebook, LinkedIn, Twitter, etc. A wide selection of journals (inclusive of 9 subjects, more than 200 journals)

Providing 24-hour high-quality service

User-friendly online submission system

Fair and swift peer-review system

Efficient typesetting and proofreading procedure

Display of the result of downloads and visits, as well as the number of cited articles

Maximum dissemination of your research work

Submit your manuscript at: http://papersubmission.scirp.org/

Or contactwjns@scirp.org 